\title{
Localización geohistórica de los feminismos latinoamericanos*
}

\section{Doris Lamus Canavae**}

La teoría feminista contemporánea se está volviendo menos irreflexivamente occidental, más internacional, más comparativa, más democrática

en sus esfuerzos por comprender las complejidades de las culturas

humanas, los órdenes sociales y sus prácticas. Al mismo tiempo, el conflicto de interpretaciones que parece ser un aspecto permanente de la teoría feminista actual no ha producido nada parecido a una sincronización fluida con el movimiento social y político denominado feminismo, en ninguno de los lugares del mundo en los que se practica.

Mary G. Dietz, (2005:180)

Resumen: El presente artículo retoma algunos de los argumentos y categorías del discurso que critica el "eurocentrismo del feminismo latinoamericano" para llamar la atención sobre las elusiones o generalizaciones en que incurre. Sin desconocer los innegables orígenes del pensamiento feminista, el artículo insiste en las particularidades de los feminismos latinoamericanos, en su localización neohistórica. Con este propósito narra los avatares de la movilización feminista de los años setenta-ochenta en la región.

Palabras clave: feminismo, localización geohistórica, eurocentrismo, movimiento de mujeres

\section{Geohistoric location of Latin American feminisms}

Abstract: The present article retakes some of the arguments and categories of the speech that criticizes the "eurocentrism of the Latin American .feminism" to draw attention on the circumventions or generalizations in which it incurs. Without unknowning the undeniable origins of feminist thought, the article insists on the particularities of Latin American feminisms, in its neohistorical location. With this intention it narrates the ups and downs of feminist mobilization of the years seventyeighty in the region. movement

Key words: feminism, geohistoric location, eurocentrism, women’s

\footnotetext{
* Este artículo forma parte de un trabajo de investigación desarrollado como tesis doctoral titulado "De la subversión a la inclusión: movimiento(s) de mujeres de la segunda ola en Colombia”, en proceso de publicación.

** Universidad Autónoma de Bucaramanga, Bucaramanga, Colombia. Email: curramba25@yahoo.com
} 


\section{Localização geohistórica dos feminismos latinoamericanos}

Resumo: O presente artigo retoma alguns dos argumentos e categorias do discurso que critica o "eurocentrismo do feminismo latinoamericano" para chamar a atenção sobre as elusiones ou generalização em que incurre. Sem desconhecer os innegables origens do pensamento feminista, o artigo faz qüestão das particularidades dos feminismos latinoamericanos, em sua localização neohistórica. Com este propósito narra os avatares da mobilização feminista dos anos setenta-oitenta na região.

Palavras-chave: feminismo, localização geohistórica, eurocentrismo, movimento de mulheres

Recibido: 28.09.2009

Aceptado: 26.10.2009

\section{Introducción}

El feminismo como teoría y práctica que cuestiona el lugar asignado a las mujeres en un sistema material y simbólico de dominación patriarcal -sistema que se reconfigura, actualiza y mimetiza en las relaciones sociales a través de tiempos y culturas-, ha tenido desde mediados del siglo XX hasta el presente, un importante desarrollo (Amorós y De Miguel, 2005). Contemporáneamente estas teorías que han pretendido explicar la subordinación de las mujeres, interpelan desde muy diversos campos discursivos, la producción de conocimientos y prácticas culturales.

Así mismo, las académicas feministas han hecho suyas teorías provenientes de diversas corrientes contemporáneas, tales como la teoría crítica, la fenomenología, el posestructuralismo, las teorías poscoloniales, el psicoanálisis lacaniano, la semiótica, los estudios culturales, el neomarxismo y el posmarxismo, entre otras, al igual que sus afines de décadas pasadas se apropiaron, enriquecieron y transformaron posturas filosóficas y políticas como el existencialismo, el marxismo, el psicoanálisis freudiano, por ejemplo. De este modo, en buena medida, el feminismo ha estado ligado y, de alguna manera, subordinado a las distintas ideologías y teorías de Occidente, sometiendo el propio debate a tales construcciones y perspectivas, diversificando las interpretaciones acerca de la subordinación femenina.

Se ha conformado pues, una compleja genealogía del feminismo que se reconstruye a mediada que emergen conflictos entre distintas posturas teóricas, éticas y políticas frente al idealizado proyecto común de "liberación de las mujeres”, asunto que también obedece a contextos específicos, locales, regionales o globales.

Algunas de estas genealogías ${ }^{1}$ reconocen el feminismo como cons-

${ }^{1}$ Ver, entre otros, Amorós, Celia y De Miguel Ana, edits. (2005), Dietz, Mary G. (2005: 179-224). 
trucción de un discurso ilustrado de emancipación de las mujeres en Occidente que emerge con la modernidad en el seno de la Revolución Francesa, la Ilustración y la Revolución Industrial, a partir de las demandas de igualdad política de mujeres como Olimpia de Gouges ${ }^{2}$, Mary Wollstonecraft ${ }^{3}$ (Godineau, en Vovelle, 1995: 422-424).

A partir de este origen indudablemente eurocéntrico del feminismo, y en el propósito de hacer visible y reconocible su historia, las teóricas y pensadoras del feminismo, han procurado reconstruir la presencia de las mujeres en Occidente, siguiendo algunos hitos u olas (Heller, 1991:123-137) que sirven de marcadores de la periodización. De esta manera, se conocen tres (y hasta cuatro) olas que siguiendo los cánones dominantes, intentan universalizar tales olas, con el riesgo de imponer una percepción que es, a la luz de los debates actuales (Mignolo: 2003), localizada, articulada a las historias particulares, los contextos y sus conflictos.

Es así como el campo de investigación construido por la teoría y las prácticas feminista se ha desarrollado a partir de los años setenta del siglo $\mathrm{XX}$ con muchas facetas, controversias y divergencias en su discurso, tensión "que no promete resolverse en ningún tipo de consenso programático ni converger en ningún tipo de terreno conceptual compartido" (Dietz, 2005:181) y que habla de la vigencia del feminismo académico, así como de las expresiones políticas que de este nada homogéneo campo discursivo, se pueden reconocer en la acción colectiva.

Esta misma vigencia la sustentan el debate y la crítica desde dentro del propio campo feminista, así como desde otros discursos particularmente relevantes y pertinentes. Una de estas críticas hace referencia a ese origen etno/euro/anglo/céntrico, ilustrado y blanco quienes, a juicio de los críticos, imponen su particular visión de mundo a mujeres de otras razas/ etnias y culturas ${ }^{4}$.

En este contexto, lo que este artículo propone es una reflexión acerca de estos juicios, no para negar lo obvio, el origen eurocéntrico del feminismo occidental y occidentalizado, sino para introducir algunos

\footnotetext{
${ }^{2}$ Feminista francesa, publica Déclaration des Droits de la Femme et de la Citoyene, escrita en 1791.

${ }^{3}$ Feminista británica, escribe en 1792 Vindication of the Rights of Woman.

${ }^{4}$ Los referidos críticos forman parte del Programa de Investigación de Modernidad/ colonialidad Latinoamericano (Escobar, 51-86, 2003) el cual ha incorporado en el debate la dimensión patriarcal del proyecto moderno/colonial. Sin embargo, su discusión se desplaza del patriarcado como objeto de crítica, autorreflexión y deconstrucción, hacia el feminismo "eurocéntrico", "blanco", en contextos latinoamericanos. Es decir, con este “desplazamiento", el debate elude el autocuestionamiento acerca del lastre patriarcal que mediante la socialización y la cultura dominante, aprendemos, interiorizamos y portamos -generalmente de modo inconsciente- hombres y mujeres en nuestras prácticas cotidianas y posturas epistémicas.
} 
matices en esta generalización igualmente riesgosa en cuanto a sus consecuencias políticas para la acción colectiva de los movimientos feministas/ de mujeres. En este sentido quiero defender algunas ideas derivadas de este debate, para pasar a ocuparme de lo que el título de este artículo ofrece acerca de los feminismos latinoamericanos.

Pretendo pues usar algunos de los argumentos de los críticos, para reafirmar mi argumentación. De este modo, y parafraseando a Mignolo -uno de los críticos del eurocentrismo del feminismo-, si su propuesta es reinscribir en la historia de la humanidad lo reprimido por la razón moderna/patriarcal, ello pasa necesariamente por reinscribir en la historia las voces y las luchas de las mujeres por romper con una sujeción cultural y política milenaria. Como bien sostiene el citado autor, la razón moderna hace abstracción de relaciones, “de género, sexuales, de jerarquías sociales, de creencias nacionales o religiosas o de prejuicios étnicos”, así como de lugares, de contextos específicos, de particularidades, añado. Ese silencio, concluye el autor citado, es expresión de una posición de poder frente a lo cual todas las diferencias enunciadas, quedan reducidas a categorías subalternas. En consecuencia, las mujeres, aun reconociendo las diferencias existentes entre nosotras, hemos sido históricamente subordinadas por la razón moderna y el poder patriarcal.

Por tanto, si reconocemos el feminismo como construcción teórica y política inscrito, en sus orígenes, en la matriz cognoscitiva euro/ etnocéntrica, es igualmente innegable que el cuestionamiento y la denuncia acerca del carácter universal y abstracto del sujeto moderno (masculino), fue labor temprana del feminismo de Occidente.

Defiendo pues la tesis de que estos orígenes no hacen del feminismo per se un discurso inherentemente occidental y eurocéntrico; reafirmo, sin embargo, en esos orígenes, una postura política, filosófica, epistémica que inaugura la visión feminista del mundo e introduce con ello transformaciones muy profundas no sólo en los paradigmas tradicionales con los cuales se había construido el conocimiento hasta entonces, sino en las propias prácticas sociales y culturales de Occidente.

No obstante, lo que me propongo aquí, si bien tiene que ver con los desarrollos de las teorías feministas a partir de los años sesenta/setenta del siglo XX, es decir, en el período reconocido como el de la segunda ola, no es de las teorías feministas del Norte que me voy a ocupar. El eje alrededor del cual gira este artículo es la acción colectiva de las organizaciones de mujeres/feministas de los años setenta en América Latina, con el propósito de mostrar sus diferencias con los feminismos del Norte, pese a compartir con aquellos un proyecto político de transformación del orden simbólicos y material patriarcal. Por esta misma vía quiero insistir en la vigencia y pertinencia de este proyecto en Latinoamérica y el Caribe, con todas las variaciones que ello demande en un contexto tan complejo y diverso como el que caracteriza la región. 


\section{Feminismos Latinoamericano de la Segunda Ola}

En América Latina se reconoce como primera ola del feminismo a la etapa sufragista (Luna y Villarreal, 1994; Luna, 2004). La segunda está identificada como un "renacer" del feminismo en los años sesenta y setenta, en el contexto de transformaciones contraculturales en Occidente (Wallerstein, 2004:345; Hobsbawm,1996:334), el impacto de la Revolución Cubana y la utopía socialista, así como procesos intensos de "modernización y desarrollo", en la mayoría de los países latinoamericana.

Así pues, aunque generalmente en los recuentos académicos de esta historia, en América Latina se usa la genealogía construida en Europa y Norteamérica, es importante anotar que los contextos históricos y las características culturales, así como los procesos políticos de América Latina y el Caribe no sólo son distintos, sino que además, internamente, hay enormes diferencias entre países, lo que es ya un argumento aunque no el único. Enfatizo en este aspecto.

Si bien los procesos que se registran bajo la denominada segunda ola parecen ser un punto de partida común, a lo largo de la segunda mitad del siglo XX estos países van a vivir, en lo político, procesos diferentes que definen ciertos énfasis en los feminismos. Es luego, en los años ochenta, y más exactamente en los noventa, con el capitalismo avanzado y el modelo neoliberal, que los feminismos latinoamericanos "se globalizan"; no obstante, ello no modifica una historia de luchas y resistencias contrahegemónicas nacionales.

Si bien los distintos aportes a la teoría feminista producida en Norteamérica y Europa (Francia, Italia, Inglaterra, principalmente) han migrado a Latinoamérica y el Caribe y han tenido influencia en el pensamiento y la acción colectiva de la región, estas influencias tuvieron que competir, en su momento, con las teorías y prácticas políticas de la izquierda latinoamericana, inspiradas en el marxismo (también eurocéntrico) y sus distintas corrientes $y$, ambas influencias, someterse a las adaptaciones (Appadurai, 2001) e interpretaciones, así como a los conflictos que estos contextos -entonces como hoy-, presentaban.

De esta manera, la teoría feminista de la segunda ola norteamericana no se replica mecánicamente en los países latinoamericanos con las mismas características, ni es asimilada sólo por académicas homólogas de las del Norte (léase blancas, de clase alta, heterosexuales...). Mas bien, lo que se evidencia desde esta época es un complejo panorama político con el cual interactúan y al cual interpelan, con distintas o similares estrategias de lucha, los movimientos en los cuales las mujeres, como activistas, intelectuales, políticas, van a ir tomando centralidad en un sostenido proceso de construcción de autonomía y de una acción política contestataria, irreverente y crítica del sistema económico y político dominante, en el cual se inscribe el patriarcado. 
“El prototipo de la activista femenina latinoamericana de este período era una ex estudiante radical militante o guerrillera y difícilmente una “señora” burguesa obsesionada con sus propios problemas, como muchos izquierdistas quisieron hacernos creer. Sin embargo, a diferencia de las feministas radicales norteamericanas, las latinoamericanas mantuvieron su compromiso con un cambio radical de las relaciones sociales de producción y de reproducción a la vez que continuaron luchando contra el sexismo dentro de la izquierda” (Saporta et al., 1994:75).

El perfil de la militante feminista en los tempranos setenta, está directamente relacionado con el ambiente político al que se enfrentan no sólo los movimientos nacientes de mujeres feministas de la segunda ola, sino todos los movimientos sociales "progresistas" y "revolucionarios" en un período de represivos regímenes militares (Chile, Uruguay, Brasil, Perú, Argentina) y de democracias formales restringidas o autoritarismo civiles que se extendían por el continente. En tal contexto, no sólo desafiaban al patriarcado y su modelo de dominación estatal militarista, sino que denunciaba junto con otras corrientes de la oposición, la opresión y la explotación económica y política.

“Las feministas de países regidos por militares pusieron al descubierto los fundamentos patriarcales de la represión estatal, el militarismo y la violencia institucionalizada, posición que gradualmente fue adoptada en términos generales por las feministas latinoamericanas” (Saporta et al., 1994: 73).

Y, pese a la exaltación en el discurso oficial de las virtudes femeninas tradicionales (Luna, 1993), las víctimas femeninas de la represión fueron violadas y sometidas a la brutalidad de los regímenes políticos autoritarios.

Así las cosas, en los países del Sur, la conciencia feminista fue alimentada por diversas experiencias en movimientos insurgentes, organizaciones políticas militantes, movimientos estudiantiles, partidos políticos progresistas y la producción de instituciones académicas políticamente comprometidas; muchas de estas militantes fueron obligadas al exilio.

Además, Latinoamérica y el Caribe, vivían la euforia de la revolución cubana, de tal manera que el otro sentimiento que albergaba el feminismo de la época era el anti-imperialismo recogido en la consigna "toda penetración es yanqui” que se leía en las paredes de las ciudades. Esto explicaría la clandestinidad en que se inició la formación de estos grupos de mujeres, muchos de los cuales evitaron el calificativo de feministas, al igual que otros no se pronunciaban contra el imperialismo (Saporta et al., 1994:77). Otra confluencia importante fue la de la Teología de la Liberación, impulsada por la Iglesia Católica y con fuerte presencia en los barrios y las comunidades. También, contrariamente a lo que dominaba en el feminismo norteamericano, como los grupos de autoconciencia ${ }^{5}$ (MacKinnon,

\footnotetext{
${ }^{5}$ Una especie de ejercicio de fortalecimiento de autoestima, de autoconocimiento, individual y en pequeños grupos, que corresponde a una estrategia típica de la segunda ola norte-
} 
1995:156-157), en Latinoamérica las organizaciones feministas orientadas por el pensamiento de izquierda se dieron a la tarea de la concientización hacia afuera, divulgando las propuestas feministas entre otras mujeres, trabajadoras, rurales y urbano-populares, articulando el feminismo con otras fuerzas sociales y políticas (Saporta et al., 1994:77).

“...al trabajar con mujeres de las clases populares, las feministas aprendieron que los denominados temas tabú tales como la sexualidad, la reproducción o la violencia contra la mujer eran de interés e importancia para las mujeres de la clase obrera, tan cruciales para su supervivencia, como las cuestiones relacionadas con el sustento diario enfatizadas por la oposición masculina” (Saporta et al., 1994:78).

Mientras los ‘compañeros' divulgaban el marxismo que separaba base y superestructura; cuerpo y pensamiento/sentimiento, las mujeres se llenaban de argumentos frente a las descalificaciones y agresiones de aquellos.

"De hecho, muchas mujeres de clase obrera, negras e indígenas en América Latina han retomado la clasificación de feminista, rehusando aceptar la tergiversación de su significado por parte de la izquierda, en el sentido de que es otra forma de opresión colonialista, y ahora insisten en que el feminismo no es ni inherentemente burgués, ni occidental, ni intrínsecamente divisorio de las luchas populares. Con ello, han expandido los parámetros de la teoría y la práctica feminista" (Saporta et al., 1994:78).

Desde su momento formativo y tal como ocurre hoy, el feminismo latinoamericano debió enfrentar la descalificación que la izquierda masculina hacía de sus luchas, sin darse por aludida en cuanto al cuestionamiento a sus prácticas patriarcales, discriminatorias y excluyentes.

“... en parte como respuesta a sus interlocutores [varones] izquierdistas, las feministas de la región tuvieron el cuidado de hacer énfasis específicamente en la dimensión latinoamericana de sus banderas. El problema de la salud de la mujer, por ejemplo, no es solamente cuestión de ejercer control sobre el propio cuerpo; las feministas latinoamericanas insisten en que también incluye la comprensión de cómo las organizaciones internacionales y las corporaciones multinacionales determinan las políticas nacionales de salud y población en sus países” (Saporta, et al., 1994:78).

Además es importante insistir en todas las formas de violencia y violaciones que se producen en estos países sobre los cuerpos de las muje-

americana y que supone ganar seguridad en sí misma necesaria para enfrentarse a lo público y político, asunto este excluido por la cultura patriarcal de la socialización femenina. Estos grupos fueron un medio y un foro importante para su desarrollo como método de análisis de la realidad, modo de organización, forma de práctica y técnica de intervención política. 
res, pues al igual que en los años setenta, en la actualidad, tanto en los casos de las presas políticas, activistas, o desplazadas de su hábitat por la guerra, son objeto de violencia sexual y tortura. Es esta violencia política, sumada a la violencia doméstica, la que se denunciaba entonces y hoy, cuando se reclama la autonomía sobre el propio cuerpo. No es un simbólico acto de “conquista” de autonomía, sino una denuncia política y demanda de respeto a la dignidad humana.

En aquellos años las expresiones de rechazo de las chilenas a la represión se articuló alrededor de la consigna que identificaría a todas las feministas de las Américas: "Democracia en el país, en la casa y en la cama”, promovida por Julieta Kirkwood y Margarita Pisano, consigna que denunciaba la negación de la persona, de su cuerpo y su sexualidad como asunto político. También estarían otras consignas como las de las madres de desaparecidos/as en Argentina, México, El Salvador, que reclamaban: "Vivos se los llevaron, vivos los queremos". Con un profundo sentido de lo privado vuelto público, sin ser feministas, confrontaron el aparato de la represión, trocando el dolor compartido en denuncia política en calles y plazas (Maier, 2001).

Las feministas latinoamericanas no retoman simplemente las banderas de las afines del Norte con la idea de que "Lo personal también es político”, asunto que de hecho replantea las nociones dominantes acerca de lo público, la política y lo político, sino que además redefinen y amplían las nociones dominantes de lucha revolucionaria, al exigir también la revolución en la vida cotidiana, afirmando que una transformación social radical debe abarcar cambios no sólo en las relaciones de clase sino también en las del poder patriarcal, cuestionando con ello las formas autoritarias de hacer política, de la izquierda masculina.

Es entonces fundamental reafirmar, por una parte, que las mujeres en América Latina han participado pública, masiva y activamente, en movimientos sociales y de protesta, por el mejoramiento de las condiciones de vida generales de las clases populares y campesinas; contra la tortura, la desaparición forzada y contra la represión política; han estado también en movimientos clandestinos y en partidos políticos de distinta orientación. Por otra parte, ser feminista implicaba una postura política centrada en un conjunto de asuntos de interés específico para las mujeres que, además, adherían a una ciertas normas de organización (participación directa, procedimientos horizontales en la toma de decisiones). Muchas de ellas participaban simultáneamente en los partidos -masculinos- y en el feminismo (Âlvarez, 2001:352), lo que se conoció como doble militancia.

Todo ello lleva a establecer una diferenciación analítica, no sólo con el feminismo del Norte, sino entre el movimiento ${ }^{6}$ (amplio) de muje-

\footnotetext{
${ }^{6}$ El uso en singular de la expresión movimiento (social), generalmente remite a la categoría de análisis, a la abstracción y no pretende simplificar la complejidad.
} 
res, política y socialmente de una composición muy heterogénea, y el movimiento feminista, también diverso y contradictorio en su interior, el cual es apenas una parte del primero. Muchas de estas feministas han participado en las tareas de organización de las luchas por la supervivencia y en los procesos de formación/concientización de estos mismos grupos, acerca de las condiciones de subordinación y su incidencia en la (no) participación política de las mujeres.

Pero el impacto del feminismo y de los movimientos de mujeres en la región ha producido, además, cambios en valoraciones sociales, culturales y simbólicas igualmente amplios:

“... el Movimiento Social de Mujeres ha significado más una redefinición del poder político y la forma de entender la política, que la búsqueda del poder o de la representación en la política formal. La acción política de las mujeres no se ha definido por los espacios de la política formal, tales como los partidos políticos, los sindicatos, los gremios y las instituciones políticas, aunque tampoco es ajeno a ellos. El movimiento ha planteado nuevos espacios en lo privado, lo doméstico y lo comunitario, y formas alternativas con contenido político, muchas de las cuales tienen un carácter subversivo ante las prácticas tradicionales” (León, 1994:14).

El movimiento de mujeres creció y se desarrolló en países sometidos a regímenes autoritarios (León, 1994) o que vivían severas alteraciones internas del orden público, como en Colombia. La movilización de las mujeres ha contribuyó a cuestionar y reconceptualizar la democracia y las concepciones que de ella se derivaron para la cultura política de fin de siglo XX. Jaqueline Pitanguy (León, 1994), sostiene que el movimiento de mujeres ha puesto en marcha un proceso de

“...recalificación de la democracia, el cual no se detiene en el ejercicio pleno de la ciudadanía sino que se hace presente en las prácticas de la vida cotidiana, las relaciones intrafamiliares, el desempeño laboral, la recreación y el tiempo libre, el ejercicio de la sexualidad, la reproducción diaria y generacional de la sociedad y, en fin, en el permanente actuar de niños, mujeres y hombres.”

El rasgo más sobresaliente de los grupos organizados de mujeres, feministas o no, en América Latina es, desde su formación, su heterogeneidad: su composición socioeconómica, ideológica, cultural, racial, étnica y política; con el tiempo, estos rasgos se han complejizado en una continua interacción con los contextos nacionales e internacionales, reafirmando su diversidad. Por ello, es poco probable hacer una descripción 'universal' del movimiento y aunque se han intentado varias maneras de abordar su definición, siempre hay algo faltante en cada esfuerzo. Uno de los deslindes difíciles es entre movimiento feminista y movimiento social de mujeres al que he aludido antes. Al respecto, una definición muy conocida, de Virginia Vargas (Mato, 2002:307), de los movimientos feministas latinoamerica- 
nos, a los que denomina "el fenómeno subversivo más significativo del siglo $\mathrm{XX}$ ”, dice:

"Dentro de esa heterogeneidad, en los inicios del despliegue movimentista podemos distinguir algunas vertientes básicas que expresaban la forma específica y diferente en que las mujeres construyeron identidades, intereses y propuestas. La vertiente feminista propiamente dicha, que inició un acelerado proceso de cuestionamiento de su ubicación en los arreglos sexuales y sociales, extendiéndose a una lucha por cambiar las condiciones de exclusión y subordinación de las mujeres en lo público y en lo privado. La vertiente de mujeres urbano populares, que iniciaron su actuación en el espacio público, a través de la politización de sus roles tradicionales, confrontándolos y ampliando sus contenidos hacia el cuestionamiento de lo privado. Y la vertiente de las mujeres adscritas a los espacios más formales y tradicionales de participación política, como los partidos, sindicatos, las que a su vez comenzaron un amplio proceso de cuestionamiento y organización autónoma al interior de estos espacios de legitimidad masculina por excelencia. Estas vertientes se multiplicarán en muchos otros espacios en la década de los 90.”

Asumo y subrayo aquí la doble condición del movimiento, en tanto feminista, por sus objetivos políticos de transformación y el marco teórico con el cual se sustenta; y de mujeres, no como una esencia unificadora, sino en tanto colectivo que comparte, además de todas las diferencias a las que me he referido, unas particularidades culturales y políticas alrededor de las cuales construye un proyecto, una utopía.

En cuanto a la categoría popular, ella tiene aquí un sentido empírico, conocida y utilizada sin mayores precisiones y aclaraciones en muchísimos textos que recogen estas experiencias de movilizaciones en diversos países de América Latina. Sin embargo, es importante enunciar al menos el o los debates que han estado y pueden estar en el origen de esta categoría. Una de las discusiones remite a la idea de pueblo y proletariado como actores sociales preconstituidos con un destino manifiesto. Sobre este uso existe la doble crítica a la no homogeneidad del "pueblo" y a la ontologización de una categoría analítica, abstracta, sin ninguna relación con la acción empírica de sus actores sociales (Archila, 2003:78-82). Derivado de este uso es el de "sectores populares" o "movimientos populares".

Una cosa si es clara: el conjunto de los así denominados populares se organizan y presentan sus demandas a partir de sus condiciones de explotación, exclusión, inequidad e injusticia social (de clase), lo que remite a la categoría gramsciana de "sectores subalternos", sin que ello nos libere del todo del privilegio que estas categorías y de quienes las asumen en su discurso, confieren a la relación y al análisis de clase, frente a otras categorías como género, por ejemplo, o, mejor aún, frente a marcos de interpretación/significación como el feminismo.

“Adicionalmente, los feminismos mantuvieron una perspectiva sub- 
versiva, de transformación de largo aliento, y un compromiso por unir las luchas por la transformación de las subordinaciones de las mujeres con las transformaciones de la sociedad y la política (...) Una fuerte desconfianza hacia los espacios políticos, especialmente los Estados, fue parte de la dinámica de los ochenta, acentuada por la existencia de gobiernos dictatoriales en numerosos países de la región. También tempranamente un sector significativo de las organizaciones feministas se expresó en dos formas de existencia: como centros de trabajo feminista, y como parte del amplio, informal, movilizado, callejero, movimiento (...), en dos dinámicas diferentes; las de las profesionales en los temas de las mujeres y las de militantes en un movimiento en formación” (Vargas, 1999: 283).

Aunque este deslinde hace referencia a los feminismos de los años ochenta, avanzada la década, unas y otras se funden cada vez de manera más compleja, en redes, iniciativas, plataformas, muchas de ellas nacionales y trasnacionales. Hoy, desde unos procesos cada vez más institucionalizados, esos grupos y organizaciones de mujeres siguen siendo parte del circuito teoría-práctica/reflexión-acción, entre las distintas expresiones del movimiento, entre académicas y militantes, entre bases sociales e intelectuales, con el acumulado del creciente proceso de ampliación del sistema educativo y el ingreso masivo de mujeres en la mayoría de estos países, lo que ha significado la calificación de amplios sectores antes excluidos por “iletrados". Aunque este proceso ha permitido la formación teórica y política de las mujeres, también ha generado nuevas formas de estratificación del movimiento, tanto nacional como internacionalmente.

En síntesis, dentro de lo que se reconoce como segunda ola del feminismo, lo que comparten los feminismos del Norte y los de estas latitudes es el sentido del resurgimiento (Ergas, 1993: 593-620) del movimiento que se había desarrollado iniciando el siglo XX, con el sufragismo -en América Latina este sí fue un movimiento de mujeres de clase alta, educadas, profesionales, y un poco más tardío que el del Norte-, y la ruptura de las fronteras que separaban lo privado y lo íntimo de lo público y político. Al fin y al cabo esa era la "causa” por la cual se luchaba. Aparte de esa continuidad/discontinuidad, el desarrollo de los feminismos en América Latina va a estar signado por condiciones y características distintivas, culturales y sociales que, de entrada, definen su localización geohistórica y política.

\section{Reflexiones finales}

Creo importante subrayar estas notas distintivas de etapas históricas del pensamiento y la acción feminista en América Latina y en cada país de la región, para seguir en la tarea de resistir a la negación de lo que las mujeres han logrado transformar en los últimos cincuenta años en el mundo, en el conocimiento y en sus vidas. En la actualidad es posible demostrar empíricamente, frente a la creencia generalizada de la ausencia de las mujeres latinoamericanas de los escenarios público/políticos (estatales y no estatales), su presencia, muchas veces articuladas a las acciones emprendi- 
das por los hombres en sus reivindicaciones por la tierra, el salario justo, la vivienda, la salud; vinculadas a las luchas por la defensa de los derechos humanos y los desaparecidos de las dictaduras o más recientemente, como en Colombia, liderando las iniciativas en defensa de la paz y contra la guerra. Así mismo, impulsando reformas legislativas que además de ampliar y promover los espacios de participación de las mujeres en ámbitos de decisión, logran agrietar estructuras sensibles del sistema patriarcal. Muchas de las conquistas por vía jurídica, en términos de derechos, igualdad, protección, reconocimiento y seguridad de mujeres, niñas y familia, en todos los países de América Latina, son producto de un largo, difícil, doloroso y silencioso trabajo de muchas mujeres, desde distintas posiciones epistémicas, políticas, de clase, culturales, entre otras. Una revolución sin “bajas”.

Por su particular condición de subordinación y exclusión (histórica, cultural y política) y tal vez por las repetidas frustraciones cada vez que se gana una batalla junto a los hombres y éstos asumen -sin ellas-, el control en las nuevas relaciones de poder, las mujeres avanzaron en la construcción de su propio proyecto de liberación, y propio supone centrarse en las condiciones de opresión a modificar, las de las mujeres, pero no porque fuese ajeno, el proyecto, a la sociedad en su conjunto, incluidos los hombres. Contrariamente a lo que piensan muchos sectores de “oposición”, el feminismo es un proyecto que pretende corregir las múltiples opresiones que en distinto grado y forma, vive la mitad de la población del planeta actualmente y, por consiguiente, construir una sociedad que no explote, excluya, maltrate, viole, discrimine a la mitad de la humanidad.

No obstante, el desafío del presente está planteado en un escenario donde las reivindicaciones desde las diferencias son dominantes y el reconocimiento de estas diferencias es apenas el punto de partida de distintas aproximaciones desde donde los feminismos contemporáneos son cuestionados y retados a ir más allá de las propuesta de la segunda ola euro/angloamericana. Hoy el mayor desafío para los feminismos está planteado por otras voces, otras historias de discriminación racial y étnica, dentro y fuera de su propia cultura. Estas historias están siendo escritas por académicas y activistas africanas, sudasiáticas y centroeuropeas, así como afrolatinoamericanas y caribeñas, chicanas, entre otras ${ }^{7}$. En este nuevo sendero intentamos aprender y aportar ${ }^{8}$

Pero, lo que es muy importante, si esta reflexión no pasa por los hombres, por sus vidas, sus prácticas y sus teorías, más difícil será el logro de aquellos ideales tantas veces enunciados y en tantas lenguas, a los largo de la historia humana.

\footnotetext{
${ }^{7}$ Una importante selección de textos se encuentra en Avtar Brah, Gloria Anzaldúa, Bell Hooks, Chela Sandoval, Khum-Khum Bhavani, Margaret Koulson, Chandra Talpade Mohanty, M. Jacqui Alexander, Aurora Levins Morales (2004). Otras inapropiables (Feminismos desde las fronteras), Madrid, Traficantes de sueños, http://traficates.net. Así mismo en Suárez Liliana y Hernández Rosalía (edits.) (2008). Ver también: Collins, Patriacia Hill, (1998: pp. 22-25).

${ }^{8}$ Ver en la bibliografía dos artículos sobre organizaciones afrocolombianas, de nuestra autoría.
} 


\section{Bibliografía}

Álvarez Sonia (2001), "Los feminismos latinoamericanos 'se globalizan': tendencias de los 90 y retos para el nuevo milenio", en Escobar et al., Política cultural \& Cultura política, Bogotá, Taurus - Instituto Colombiano de Antropología e Historia.

Abu-lughod (ed.) (2002), Feminismos y modernidad en Oriente Próximo. Colección Feminismos, Ediciones Cátedra, Madrid.

Appadurai, Arjun (2001), La modernidad desbordada. Dimensiones culturales de la globalización, Buenos Aires, FCE.

Amorós, Celia y De Miguel Ana (Editoras) (2005), Teoría feminista de la Ilustración a la globalización, Editorial Minerva, España, (3 volúmenes).

Brah, Avtar, Anzaldúa Gloria, Bell Hooks, Sandoval Chela, Khum-Khum Bhavani, Koulson Margaret, Mohanty, Chandra Talpade (2004), Otras inapropiables (Feminismos desde las fronteras), Madrid, Traficantes de sueños, http://traficates.net.

Dietz, Mary G., (2005), "Las discusiones actuales de la teoría feminista”, en Debate Feminista No 16, Vol. 32, México, pp. 179-224.

Escobar, Arturo, (2003) "Mundos y Conocimientos de otro modo, El programa de investigación de modernidad/colonialidad latinoamericano". Tabula Rasa, Bogotá - Colombia, No.1: 51-86.

Ergas, Yasmine (1993), "El sujeto mujer: el feminismo de los años sesenta-ochenta”, en Historia de las Mujeres, España, Taurus, Tomo 5, Siglo XX.

Godineau, Dominique (1995), “Las mujeres”, en Vovelle, Michel y otros, El Hombre de la Ilustración, Madrid, Alianza Editorial.

Hobsbawm, Eric (1996), Historia del siglo XX 1914-1991, Barcelona, Crítica.

Heller, Agnes (1991), "Los movimientos culturales como vehículo de cambio”, en Viviesca y Giraldo (comp.). Colombia el despertar de la modernidad. Santa Fe de Bogotá, Foro Nacional por Colombia.

Kirkwood, Julieta (1990), Ser política en Chile: los nudos de la sabiduría feminista, Chile, Cuarto Propio.

Lamus, Doris, (2009), "Mujeres negras/afrocolombianas en los procesos organizativos en Colombia. Un aporte al estado del debate", Revista Reflexión Política, año 11, No. 21, junio, pp. 108-125, IEP-UNAB, Colombia. 
Ídem (2008), “El lugar político de las mujeres en el movimiento negro/ afrocolombiano”. Revista Reflexión Política No. 20, diciembre, pp. 237-257.

Ídem (2008), "Resistencia contra-hegemónica y polisemia: conformación actual del Movimiento de Mujeres/Feministas en Colombia”, Revista La manzana de la discordia, Año 3, No.5, Junio.

Ídem (2007), “La construcción del movimiento latinoamericano de mujeres/feministas: aportes a la discusión teórica y a la investigación empírica, desde la experiencia en Colombia”. Reflexión Política N.18, pp. $118-132$.

Ídem (2008), “La Agenda Global de las Naciones Unidas para “la mujer””, Revista Polis, Universidad Bolivariana de Chile, Santiago, No. 20, Agosto. http://www.revistapolis.cl/polis\%20final/20/inicio.htm

Ídem (2007), De la subversión a la inclusión: movimiento(s) de mujeres de la Segunda Ola en Colombia, 1975-2005. Tesis doctoral (en proceso de publicación).

León Magdalena (comp.) (1994), Mujeres y Participación Política. Avances y desafíos en América Latina, Bogotá, Uniandes y Tercer Mundo Editores.

Luna, Lola G. (1993), Los movimientos de mujeres en América Latina y la renovación de la historia política, Centro de Estudios de Género Mujer y Sociedad, Universidad del Valle, Santiago de Cali, Editorial Manzana de la Discordia.

Ídem (2004), El sujeto sufragista, feminismo y feminidad en Colombia, 1930 -1957, Cali, Centro de Estudios de Género Mujer y Sociedad, Universidad del Valle, Ediciones La Manzana de la Discordia.

Ídem y Villarreal, Norma (1994), Historia, Género y Política. Movimientos de Mujeres y Participación Política en Colombia, 1930-1991. Seminario Interdisciplinar Mujeres y Sociedad - Comisión Interministerial de Ciencia y Tecnología, Barcelona.

Mackinnon, Catherine (1995), Hacia una teoría feminista del Estado, España, Ediciones Cátedra, Universitat de Valencia.

Maier, Elizabeth (2001), Las madres de los desaparecidos ¿un nuevo mito materno en América Latina? UAM-El Colegio de la Frontera Norte, México, La Jornada Ediciones.

Mignolo, Walter (2003), Historia locales/Diseños globales. Colonialidad, Conocimiento subalterno y pensamiento fronterizo, Madrid, Akal. 
Rowbotham, Sheyla. (1980), La mujer ignorada por la historia, Madrid, Debate.

Spivak, Gayatri Chakravorty (2003), “¿Puede hablar el subalterno?”, Revista Colombiana de Antropología, Vol. 39, Bogotá, enero-diciembre, pp. 297-364.

Saporta Nancy, Navarro Marysa, Chuchryk Patricia y Álvarez Sonia (1994), "Feminismo en América Latina: De Bogotá a San Bernardo", en León Magdalena (comp.) Mujeres y Participación política. Avances y desafíos en América Latina, Bogotá, Uniandes y Tercer Mundo Editores.

Suárez Liliana y Hernández Rosalía (edits.) (2008), Descolonizando el Feminismo: teoría y prácticas desde los márgenes, Barcelona, Cátedra. Vargas, Virginia (1999), "Los nuevos derroteros a fin de milenio, derechos y autonomía”, en Isis Internacional. 28, 283-296.

Ídem (2002), “Los feminismos latinoamericanos en su tránsito al nuevo milenio (una lectura político personal)”, en Mato, Daniel (Coord.) Estudios y Otras Prácticas Intelectuales Latinoamericanas en Cultura y Poder. 307-316. Caracas, Consejo Latinoamericano de Ciencias Sociales (CLACSO) y CEAP, FACES, Universidad Central de Venezuela. 